\title{
Origen, necesidad y filosofía de la administración y las relaciones humanas
}

Manuel Zevallos Vera * http://dx.doi.org/10.21503/lex.v10i10.230

* Ha sido rector de la Universidad San Agustín de Arequipa, primer Presidente de la ANR, miembro de CONAFU, profesor y Doctor en filosofía con más de 50 años de servicios docentes en pregrado posgrado y posdoctorado; autor de 20 libros y más de cien ensayos; doctor Honoris Causa de la UAP; Profesor Emérito de la Universidad San Agustín de Arequipa; Amauta del Perú; premiado por su labor intelectual en la III Feria Internacional del Libro en su ciudad natal Arequipa.

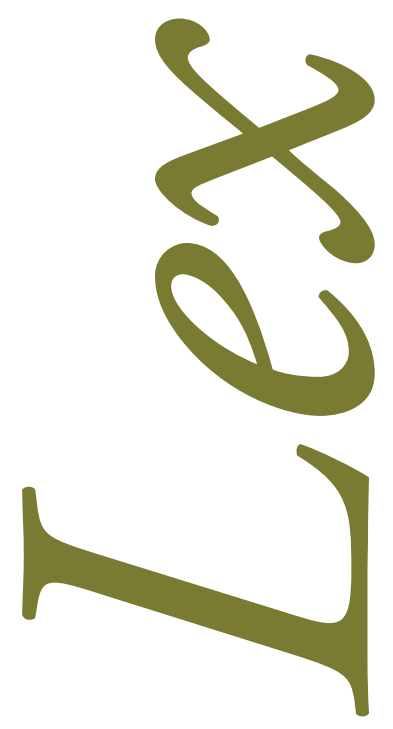



$\mathrm{D}$ esde que el hombre aparece sobre la faz de la Tierra como creación divina de Dios o de los dioses o como producto del proceso evolucionista de la naturaleza, por necesidad vital y por el avance de la civilización y la cultura, ha ido creando, a través de miles de años, organizaciones, instituciones, agrupaciones, servicios, industrias, empresas, lenguajes para entenderse, sistemas, etc. Este cúmulo de creaciones requería y requiere, para obtener relaciones y resultados eficientes y eficaces, un ordenamiento sistemático, técnico, positivo, inteligente que se denomina Administración, y que por necesidad del progreso social humano se ha convertido en una profesión incorporada en los currículos de institutos y universidades.

\section{EVOLUCIÓN HISTÓRICA DE LA ADMINISTRACIÓN}

Desde los albores de la civilización y la cultura humana, los pueblos han requerido organizarse, administrarse, planear, gobernarse para que su vida familiar o grupal, privada o pública tenga la seguridad y fortaleza de un progreso sostenido y estable. Rastreando el desarrollo de las sociedades pretéritas y actuales, ofrecemos los siguientes ejemplos:

\section{En la Edad Antigua}

- Egipto (4000 a.C.). Los egipcios contaban con dirigentes capaces de planear, organizar y controlar a miles de trabajadores en la construcción de sus monumentos (para levantar una sola pirámide se utilizaron los servicios de más de 100 mil personas durante veinte años).

- China (2000 a.C.). Utilizaban una junta de consejeros y técnicos para cada caso en que debía de tomarse una decisión importante.

- Babilonia (1800 a.C.). Aprobó el Código de Hammurabi, que legisla y prescribe el uso del control escrito y los testimoniales, derechos y obligaciones individuales y sociales.

- Grecia (400 a.C.). Sócrates postula la universalidad de la administración.

- Platón, en su libro La República da sus puntos de vista sobre la administración de los 
negocios públicos y el principio de especialización, y en cuanto a la educación de los niños y juventud, plantea que esta debe estar a cargo y control del estado, lo que requiere una administración especial.

- Aristóteles (300 a.C.). En su libro La Política señala tres tipos de gobierno en la política:

a) Monarquía: gobierno de una sola persona.

b) Aristocracia: gobierno de la clase alta.

c) Democracia: gobierno del pueblo.

Cada tipo de gobierno exige una administración singular.

- Roma (175 a.C.). Una de las civilizaciones que más influyó en el pensamiento administrativo fue el pueblo romano, que marcó las bases más importantes de la sociedad moderna (Derecho Romano) y define todas las figuras del Derecho Civil. Contaba con administradores que recibían el nombre de gestores o mandatarios.

Durante la Edad Media, la Iglesia Católica Romana representa un ejemplo interesante de la práctica de la administración, la estructura actual de la Iglesia. En ese tiempo se definieron con mayor rigor sus objetivos y doctrinas. La autoridad final se centralizó en Roma. Se creó una estructura jerárquica simple, que en lo básico aún prevalece tras casi 2000 años.

\section{En la edad Moderna y Contemporánea}

- Adam Smith (1780). Se le conoce por su contribución a la doctrina de la economía clásica. Su análisis en La riqueza de las naciones, que se publicó en 1776, incluía un brillante argumento sobre las ventajas económicas que las organizaciones y la sociedad podrían obtener de la división del trabajo. Fue un teórico del sistema capitalista.

Smith postuló que la división del trabajo aumenta la productividad al incrementar la habilidad y destreza de cada trabajador, ahorrar el tiempo que, por lo general, se pierde al cambiar de actividades y crear inventos que ahorraban trabajo. La amplia popularidad actual de la especialización del trabajo (tanto en puestos de servicios como la enseñanza y la medicina como en las líneas de ensamble en las plantas de automóviles) se debe sin lugar a dudas a las ventajas económicas que señaló hace más de 200 años Adam Smith.

- Revolución Industrial. Tiene sus inicios a fines del siglo XVIII y principios del siglo XIX. Consiste en un cambio de los modelos de producción. Aquella producción hecha a mano y limitada pasa a ser una producción hecha a máquina y en serie. Donde se presenta con mayor fuerza es en Inglaterra, pero también hay cambios notorios en Francia, Italia, Alemania, EE.UU, etc., 
Existen reacciones de todo tipo en la revolución industrial, pero dentro de las más importantes está la Revolución Socialista Marxista, cuyos principales exponentes son Carlos Marx y Federico Engels, que proponen los siguientes cambios en su obra El capital (1848):

- La desaparición de la propiedad privada.

- La creación de un sistema que logre satisfacer las necesidades del proletariado.

- Que el proletariado ocupe el poder como resultado de la lucha de clases, que según ellos es el motor de la historia.

- Frederick Winslow Taylor (1856 - 1915). La famosa obra de Taylor titulada Principies of Socientific Management se publicó en 1911, y es una de las mejores exposiciones de filosofía de la Administración.

- Henry Fayol (1841 -1925). Suele ser recordado como el fundador de la Escuela Clásica de Administración, no porque fuera el primero en estudiar el comportamiento gerencial, sino porque fue el primero en sistematizarlo. Fayol pensaba que las prácticas administrativas aceptadas siguen ciertos patrones, los cuales se pueden identificar y analizar. A partir de esta premisa básica, trazó el proyecto de una doctrina congruente de la Administración, la cual sigue conservando mucha fuerza hasta la fecha.

La sociedad democrática contemporánea preconiza la defensa de la propiedad privada y la alternancia en el poder político mediante elecciones libres, que es el régimen que mayoritariamente rige en el mundo actual.

\section{ESTADO ACTUAL DE LA TEORÍA ADMINISTRATIVA}

En la actualidad, la teoría administrativa estudia la administración de empresas y demás tipos de organizaciones desde el punto de vista de la interacción e interdependencia de las cinco variables principales, cada una de las cuales es objeto específico de estudio de una o más corrientes de la teoría administrativa. Las cinco variables básicas (tarea, estructura, personas, tecnología y ambiente) constituyen los principales componentes en el estudio de administración de las empresas. La adecuación de estas cinco variables constituye el principal desafío de la Administración.

\section{El papel administrador del hombre como individuo y como ser social}

El hombre como individuo. Todas las ciencias se ocupan del hombre, desde las ciencias naturales, que tienen que vérselas con el estudio de objetos que no son producto de la libre intencionalidad del hombre pero es el agente que las organiza, las entiende, las legaliza y las pone a su servicio, hasta las ciencias culturales, sociales y filosóficas, que giran en torno del problema humano. Dentro de todas ellas, es la antropología la que se ha dedicado a su 
estudio concreto, recogiendo y auxiliándose del resultado de todas las ciencias. Es así como la antropología científica estudia al hombre en cuento ser psicofísico o simplemente, en cuanto entidad morfológica y biológica, tanto como ser vivo o muerto.

La antropología cultural o social lo estudia como ente concreto productor de bienes culturales. Podemos decir que el hombre genera un mundo de cultura, en cuya complejidad vive y se desarrolla, pues las ciencias culturales estudian los objetos que son producto de la libre creación del hombre, es decir, de todo aquello en que aparece la mano, el sello, la huella, la voluntad del hombre.

La antropología filosófica considera al hombre no solo en su ser natural, sino, fundamentalmente, en su ser esencial; y no solo en su puesto dentro de la naturaleza, sino dentro del universo, en su trascendencia espiritual. El hombre como ser físico, como unidad individual, dotado de una biología y fisiología comunes a la especie, es singular en su concreción individual y poseedor de una psicología diferenciante de individuo a individuo. Podemos sostener que no hay dos hombres iguales, pero a pesar de esta infinita desigualdad, existe una permanencia armónica de la dimensión individual.

El hombre como ser social. No se concibe al hombre aislado del grupo social, no obstante lo cual, el hombre trata de imponer su singularidad, su autonomía y su personalidad. El hombre como individuo es instintivo, controlado por su razón y por su conducta moral.

Este individualismo no puede mantenerse indefinidamente, pues se siente impotente para subsistir ante la fragosidad de sus condiciones vitales, y a cada momento va sufriendo los impactos del sentimiento de conservación individual, que quiere ganar para sí el favor de los demás, el servicio de los demás, la defensa de los demás.

Surge así el sentimiento gregario como una forma instintiva de conservación individual. El hombre se une, se junta, convive, para preservarse, para defenderse, para subsistir como individuo.

El individualismo lo lleva a acercarse hacia los demás, especialmente en momentos de peligro, pero cuando el peligro desaparece y se siente fuerte, pelea la presa, se aparta del grupo momentáneamente (el troglodita e incluso el hombre moderno), pero tiene que volver al grupo por su instinto gregario, por necesidad, porque es incapaz de autoabastecerse individualmente.

La historia de la humanidad podemos decir que es la historia de la lucha descarnada entre el instinto gregario y el instinto individualista, pero no como una lucha de extremos irreconciliables, irreductibles, adversos, sino como un imperativo de integración de lo individual en lo social. Solo en la literatura y en el mundo de la ficción puede darse un hombre 
aislado del grupo social, tal como ocurre en la obra de Daniel Defoe Robinson Crusoe", que narra la historia de este personaje, abandonado en la isla Juan Fernández del Océano Pacífico y que se ve obligado a sobrevivir por propio esfuerzo y a producir todos sus objetos vitales.

El hombre es fundamentalmente un ser social que vive y sobrevive porque recibe bienes y servicios de su comunidad. Todo lo que lleva puesto, los objetos con que se entretiene, su alimentación, lecturas, viajes, cuidado de su salud, ejercicio de un oficio o profesión, etc. son producto social, colectivo. Los individualismos autosuficientes son absurdos, suicidas, no existen.

El hombre social se debate entre el reino de la necesidad y el reino de la libertad. Por su necesidad, el hombre se somete a las normas, las costumbres, las leyes y el orden que imponen el régimen político-jurídico de un Estado y una sociedad determinada. Es un ser de necesidades individuales, familiares y comunitarias, pero también es un ser afectado de libertad. Tiene conciencia de libertad, cuyo sentimiento lo diferencia de la animalidad, porque es un ser racional.

Necesidad. Es el carácter de aquello que no se puede prescindir, de lo que no puede evitarse. Respirar es una necesidad del hombre. Conservar su salud, educarse, trabajar, alimentarse, progresar son actividades necesarias. Necesidad es pues todo aquello que tiene fuerza y nos obliga a cumplirlo. Por otra parte, no todo lo que es necesario es posible, ni todo lo posible es necesario.

El hombre es un animal de necesidades, y prácticamente las relaciones humanas resultan un intercambio de servicios para satisfacer necesidades individuales o sociales.

Libertad. Es el poder de obrar o de no obrar (de hacer o no hacer), de escoger. El deber y el derecho suponen la libertad. Se puede sacrificar la libertad en aras de la necesidad.

La libertad es el estado opuesto a la servidumbre o al cautiverio, a la esclavitud.

Personalmente, defino la libertad como la capacidad de respuesta del hombre frente a la relación hombre-mundo; del diálogo permanente entre el hombre y el mundo provienen las respuestas religiosas, míticas, filosóficas, científicas, jurídicas, éticas, estéticas, axiológicas, deportivas, lúdicas, cibernéticas, etc. Por su conciencia de libertad, a cada instante el hombre sacrifica su mundo de necesidad. Por su libertad, y para satisfacer necesidades materiales, espirituales, culturales, estéticas, políticas, tecnológicas, económicas, científicas, etc., rompe con moldes, con modelos, con sistemas imperantes y crea nuevas formas, instituciones, ideas, doctrinas, a veces bien recibidas por el grupo social y otras veces en conflicto y discordia con las normas sociales establecidas. De aquí surgen las buenas y malas relaciones. 
El hombre se agrupa por su conciencia de libertad, en sectas, religiones, partidos políticos, países, ideologías, escuelas filosóficas, literarias o estéticas, oficios, profesiones, concepciones sociales y económicas: liberalismo, controlismo, monetarismo. Hasta en los deportes se dan los opuestos (clásicos Alianza - Universitario).

En los negocios, las cosas aún se agravan más, y se manifiestan en relaciones contradictorias: oferta, demanda, clientelaje, relaciones raciales.

Génesis, crisis y renacer de las relaciones humanas

El problema del hombre, considerado como un ser individual y necesariamente social, nos conduce al complejo problema de las relaciones humanas, que se inician desde el momento que existe un contacto y una relación entre dos o más hombres. A partir de esta realidad humana, si nos remitimos a sus orígenes bíblicos, tenemos que convenir que las relaciones humanas han tenido un desgraciado inicio, a partir de la pareja Caín y Abel.

¿Cómo podemos definir las relaciones humanas? Las relaciones humanas son el resultado de la consideración, la estima, el respeto, las conductas, los sentimientos y las razones positivas o negativas que se mantienen entre las personas individuales o sociales, naturales o jurídicas. De estas relaciones se derivan los deberes, obligaciones y derechos.

De tal definición analítica, se deduce que los hombres tenemos que vernos con buenas, regulares o malas relaciones.

¿Qué se puede hacer para establecer, a un nivel racional, las relaciones humanas en el mundo, dentro del muy crítico y conflictivo panorama actual? De tales relaciones se generan tres tipos, modos o niveles de vida, vale decir, tres mundos o estructuras vitales, dentro de los que el hombre desarrolla su conducta y comportamiento individual y social. Esto nos conduce a considerar al hombre como una unidad ético-moral.

a) Vida privada. Corresponde al marco personal, individual y familiar de las personas, como las relaciones matrimoniales, interfamiliares. Tiene que ver con las decisiones personales del grupo familiar - manejo libérrimo de su economía, ahorros y bienes materiales—, con un estilo de vida, con los hábitos y costumbres propios, así como con el desarrollo personal de sus intereses y circunstancias para llegar a una prosperidad o para decaer en crisis por hechos adversos.

La vida privada está limitada, en sus aspectos trascendentes, por las leyes, las buenas costumbres y la moral, pero cabe la informalidad. A pesar de todo ello, la vida privada se caracteriza justamente por su privacidad, que se defiende a toda costa, pero cuyas conexiones, resultados y consecuencias rompen con tal privacidad, y recaen sobre ella, aunque no se 
quiera, la opinión y juicios externos y en algunos casos hasta la fiscalización de la comunidad (censura y penalidad).

b) Vida pública. Está dada por el conjunto complejo de relaciones políticas, económicas y sociales y por las funciones extrapersonales y extrafamiliares que asume el hombre en los planos institucionales, sociales, nacionales e internacionales. La vida pública necesariamente es fiscalizada por la sociedad a través de sus órganos competentes, y su ámbito está definido por las constituciones, las leyes y las normas morales, aunque también, como lo demuestra la experiencia histórica y la problemática actual del mundo, se peca de mucho descontrol e informalidad, sobre los que se reacciona tardía y extemporáneamente, con consecuencias dolorosas y perjuicios irreparables para las instituciones, los países y la humanidad.

El punto problemático surge con el llamado sector privado o de la empresa privada, que lo podemos incluir en el mundo de la vida privada en tanto son personas o grupos dueños de sus capitales.

Personalmente pienso que este tipo de empresas, manejadas por entes no estatales, por tenérselas que ver con relaciones sociales, con clientela y con responsabilidades económicas de terceros, con servicios y bienes de consumo que ingresan al mercado, con trabajadores y servidores sometidos a regímenes legales muy precisos, son entidades que no encajan estrictamente en el sector de una vida Privada, sino que más bien se halla muy comprometida con la vida pública, hoy más que nunca, puesto que es notable la participación activa del sector privado en el desarrollo político, económico y social del Perú (caso CONFIEP).

Y qué decir de las llamadas empresas autónomas, que son entes de vida pública y cuya autonomía no las libra de su responsabilidad pública (universidades, iglesias, fundaciones).

c) Vida intima. Es el centro de la eticidad. Por su vida íntima, el hombre se siente responsable de sus actos y, por tanto, un ser libre, dueño de una conciencia interna que ineludiblemente lo autofiscaliza, al margen de lo que los demás digan o juzguen por las apariencias u opiniones que tengan de sus actos. El hombre es responsable de su hacer frente a su propia conciencia.

Es corriente la confusión o identificación que hacemos entre vida íntima y vida privada. Se pretende soslayar la mala conducta individual, aduciendo que se trata de su vida íntima, en la que nada ni nadie pueden inmiscuirse y menos juzgar. Esta actitud es falsa y equivocada. Resulta un autoengaño, pues en la vida privada alguien puede cometer canalladas, mentir, traicionar, odiar, perjudicar, robar, matar, etc., y seguir aparentando que se trata de un hombre honorable; pero a lo que no puede engañar ni traicionar es a su vida íntima, a su conciencia moral. A los demás de podrá engañar por cierto tiempo, pero no por toda la vida, en tanto 
su vida íntima estará ahí, impertérrita, acusadora, contrita de tanta canallada, dispuesta al arrepentimiento interior y a su confesión con Dios, a quien no se puede engañar. La vida sexual es lo más característico de la vida íntima, hasta no pecar de inconducta. El "conocerse a sí mismo" de Sócrates es una norma ética que nos obliga a tener conciencia de nuestros actos y conducta y no aparentar lo que no somos ni valemos, a fin de superarnos y perfeccionarnos como personas.

\section{CONSECUENCIAS, RESULTADOS Y CONCLUSIONES}

Podemos decir que las relaciones humanas resultan y son producto de las interrelaciones de conductas y comportamientos individuales y colectivos de los hombres en sus vidas pública, privada e íntima. Las relaciones humanas constituyen, pues, un complejo total de la vida individual y social del hombre.

Podemos hablar de buenas o malas relaciones, de relaciones rotas o suspendidas, críticas, inamistosas o amistosas, fraternas, solidarias.

Pero, ¿a quién podemos culpar de nuestras malas y conflictivas relaciones?, ‘a quién podemos agradecer de las buenas y fraternas?, ¿ a los dioses, a las vírgenes, a los santos, a los horóscopos, a factores imponderables? Estas no son sino formas de eludir nuestra responsabilidad, de escapar de nuestra culpa. Los causantes de las buenas o malas relaciones somos los propios hombres, los agentes de conducta de los actos de los que somos responsables.

\section{Perspectivas futuras de la Administración}

En las próximas décadas, la tarea administrativa será incierta y excitante, pues deberá enfrentar cambios y transformaciones llenos de ambigüedad e incertidumbre. El administrador deberá enfrentar problemas cada vez más diversos y más complejos que los anteriores, y su atención estará dirigida a eventos y grupos situados dentro o fuera de la empresa, los cuales le proporcionarán información contradictoria que dificultará su diagnóstico y la comprensión de los problemas que debe resolver o las situaciones que debe enfrentar: exigencias de la sociedad, de los clientes, de los proveedores; desafíos de los competidores; expectativas de la alta administración, de los subordinados, de los accionistas, etc. Sin embargo, estas exigencias, desafíos y expectativas implican profundos cambios que sobrepasan la capacidad del administrador para acompañarlos de cerca y comprenderlos de manera adecuada. Estos cambios tienden a aumentar debido a la inclusión de otras nuevas variables, a medida que el proceso se desarrolla y crea una turbulencia que perturba y complica la tarea administrativa de planear, organizar, dirigir y controlar una empresa eficiente y eficazmente. El futuro parece complicar la realidad, puesto que innumerables factores sorpresivos producirán impactos profundos en las empresas. 
Toda empresa, de cualquier tipo, requiere un organismo directivo (directorio), un órgano ejecutivo (gerentes y administradores) y un cuerpo de apoyo (logística humana y tecnológica). Ellos constituyen, en conjunto e integradamente, la administración pública y privada, sin la cual sería imposible el progreso y desarrollo ordenado del mundo humano.

Recibido: 10/08/2012

Aprobado: 09/09/2012 
